\title{
Sustainable Transportation: Lessons from London
}

\author{
Andrea Broaddus
}

PhD candidate; UC Berkeley.

\begin{abstract}
Andrea Broaddus was a Visiting Scholar at University College London, researching the London Congestion Charge policy and its impacts on travel patterns and location choices. In May 2014 she guest lectured at Cal Poly's City and Regional Planning Department, presenting her research and discussing opportunities for experimentation in the United States. Her talk is summarized in this article.
\end{abstract}

\begin{abstract}
became interested in congestion charging as a policy 'stick' - the kind of policy that complements policy 'carrots' like great bike, pedestrian and transit infrastructure, and can make them much more effective as part of a sustainable transportation strategy. Congestion charging is a method of influencing travel behavior using pricing. During peak congestion hours in London, vehicles are charged a daily fee of $£ 11.50$ (roughly \$19), to enter the central business district. The policy was adopted in 2003 to deter private vehicle trips and encourage people to travel by other modes. It has been highly effective.
\end{abstract}

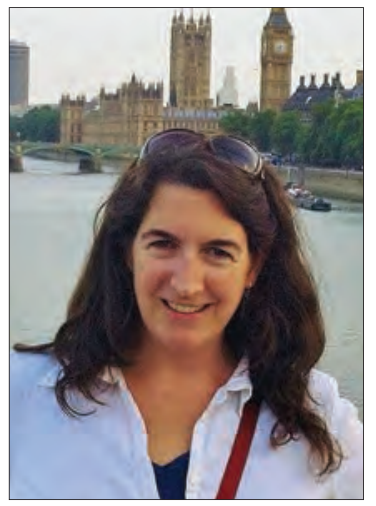

I am convinced, after having lived in London for a year, and interviewed dozens of experts there, that sustainable transportation policies need to work together. London set mode shift as an explicit policy goal, and implemented an aggressive combination of measures to get there. What we have in London is a great case example of mode shift at scale. The lesson learned is that you cannot reduce vehicle miles travelled (VMT) and achieve mode shift by doing one disparate thing at a time. You need to do a lot of things simultaneously, linked together, and they incrementally add up to big changes.

There are a few examples of congestion charging in California, such as the Bay Bridge in San Francisco, where drivers are charged a higher price to cross the bridge during peak hours, or tolled express lanes on I-10 and I-110 in Los Angeles, where drivers can opt to pay a fee to use express lanes otherwise reserved for high occupancy vehicles. These are examples of managing peak demand in a single corridor. In London, the congestion charge is applied to all roads in a central area of about four square miles, to manage demand for driving throughout that area. It is also in effect for the entire business day, from 7:00 am until 6:00 pm. The charge is enforced by a ring of cameras that match the license plates of cars entering the charged area with a list of payments.

London is one of a handful of cities in the whole world that has actually implemented a (citywide) congestion charging scheme because they tend to be unpopular in places where a lot of people drive. The most famous example is Singapore. In London, only about $10 \%$ of people were commuting by car when the congestion charge went into effect in 2003, which helped make it less controversial. Public support was won over by dedicating all revenues raised from the congestion charge to public transportation improvements. The congestion charge nets about $£ 130$ million ( $\$ 200$ million) per year, most of which is invested in bus services (Transport for London, 2008).

\section{A long-term trend of mode shift}

The impacts of London's congestion charge policy have been well documented. The congestion charge area was expanded in 2008 to include a 'western extension' area, but this was removed area has become part of the city fabric, and is not controversial today (Figure 1). When it was introduced, the fee was $£ 5$, but it is currently $£ 11.50$ (about \$19.50). The increases were necessary both to cover the cost of the expansion, and to remain competitive with public transit fares, which have also been increasing. There are exemptions for low emission vehicles and disabled drivers, and a fleet discount for freight vehicles. Traffic volumes fell by an estimated 80,000 vehicles per day (20\%) within the central area when it was implemented, and have remained stable over the decade (Transport for London, 2013). Transit use increased $14 \%$ in the first year and has continued increasing over the decade (Transport for London, 2008). A bicycling renaissance is underway, and the number of people entering central London by bike has doubled since 2003 (Transport for London, 2013). New pedestrian and bicycle infrastructure has been built and pedestrian injuries and fatalities have decreased.

My study looks at how central London has been changing over the past 20 years, in terms of population, employment, land in response to residents' complaints in 2011. The central charged 
use, and travel behavior. There was steady population growth from 1993 when the city had 6.8 million residents until 2013 when it had 8.5 million (21\% growth) (Transport for London, 2013). Employment growth, while cyclical, also trended steadily upward, from 3.8 million jobs in 1993 to 5.2 million in 2013 (37\% increase) (Transport for London, 2013). Both of these factors drove growth in travel. The estimated average daily number of trips made by Londoners grew from 20.8 million to 25.9 million (25\% increase) over this timeframe (Transport for London, 2013).

The impacts of the congestion charge were most noticeable in central London. Figure 2 shows trips entering central London during the weekday morning peak from 1996 to 2009, by mode. The number of people entering central London grew from 993,000 to 1.1 million over this timeframe (10\% increase) (Transport for London, 2010). The proportion using a car was stable until the early 2000s, when it began to decline and bus ridership began to increase. By 2003, when the congestion charge was introduced, car commuting had already fallen substantially, and more people bus riders exceeded drivers for the first time.

Behavioral change, especially of people switching out of cars, accounted for a significant portion of the mode shift trend. Table 1 shows a calculation of the changes in the number of people commuting by public transit and private auto from 1996 to 2002, and from 2002 to 2009. These can be considered pre- and post-congestion charging periods. Between 1996 and 2002, 75,000 people entered the workforce commuted to central London. Yet the number of people commuting by public transit increased by 119,000 . So if we assume that all the new commuters took transit, that means approximately 44,000 people (the difference) must have switched modes. This seems to be explained by noticing that 34,000 fewer people were commuting by car, 12,000 fewer by taxi, which adds up to 46,000 fewer people using those modes. Accounting for 2,000 additional bicycle commuters, that leaves 44,000 people who switched out of cars and taxis onto public transit.

A similar calculation may be done for the change from 2002 to 2009 , but in this case people were clearly switching to bicycles

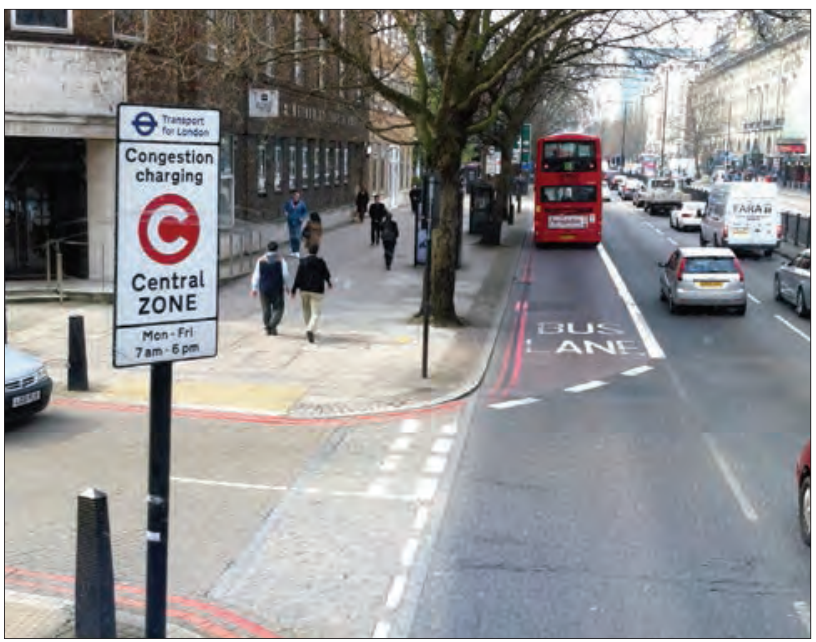

Figure 1: The congestion charge boundary on Euston Road, where two of six lanes are dedicated for bus priority.

as well. In this case, assuming all new commuters were transit riders, 21,000 people must have switched out of cars to transit (as no more switched away from taxis). The remaining 15,000 switched from cars to bikes, with some rounding errors. Table 1 reveals that the congestion charge was not the original impetus for people switching modes in central London. It came into effect during a period when people were already switching to transit in droves, and served to continue the trend.

\section{How was mode shift achieved?}

Why were people abandoning their car for commuting in the pre-congestion charge period? Congestion was worsening in central London throughout the 1990s, which is the main reason that the idea of congestion charging arose. Increasing traffic congestion was making cars and taxis inefficient and unreliable. In 1997, the average travel speed in central London during the morning peak was 15.2 kilometers per hour (9.4 $\mathrm{mph}$ ), and by 2002 it had slowed to 14.2 kilometers per hour on average (8.8 mph) (Transport for London, 2003).
Figure 2: Trend of people entering central London, weekday morning peak (in thousands; $1996=100$ ). From Transport for London, 2010.

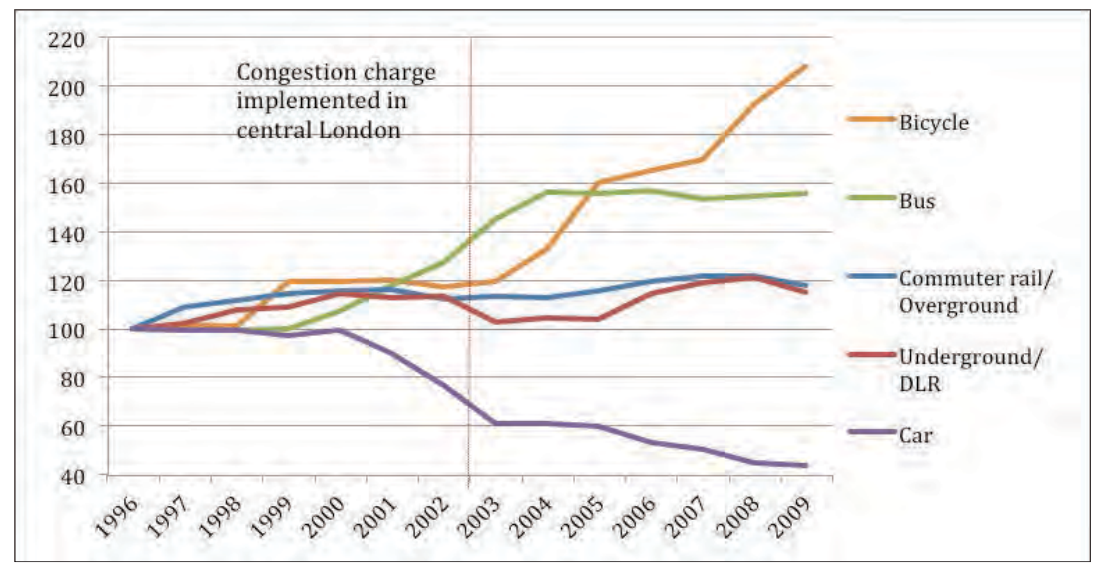




\begin{tabular}{|c|r|r|r|r|r|}
\hline & $\begin{array}{c}\text { Public } \\
\text { transit }\end{array}$ & $\begin{array}{c}\text { Private } \\
\text { auto }\end{array}$ & \multicolumn{1}{c|}{ Taxi } & Bicycle & \multicolumn{1}{c|}{$\begin{array}{c}\text { Total } \\
\text { commuters }\end{array}$} \\
\hline 1996 & 800 & 154 & 29 & 10 & 993 \\
\hline 2002 & 919 & 120 & 17 & 12 & 1,068 \\
\hline Change & 119 & -34 & -12 & 2 & 75 \\
\hline \multicolumn{7}{|c|}{} \\
\hline 2009 & 968 & 85 & 17 & 27 & 1,096 \\
\hline Change & 49 & -35 & 0 & 15 & 28 \\
\hline
\end{tabular}

Table 1: Change in number of people commuting by public transit and private auto (thousands). From Transport for London, 2010.

Starting in 1997, when a pro-transit national government came to power in the UK, investment in transit increased dramatically. This was a complete turnaround from previous decades of neglect, during which London's transit system was fragmented and deteriorating. From 1997 to 2012, London added four new extensions to its Docklands Light Rail (DLR) system, extended the Jubilee line of the Underground, and built a new suburban tram system called Croydon Tramlink. From 2007 to 2012, major upgrades were made to the city's commuter rail network, including extensions to form a new orbital service called the Overground. Massive investments were made to improve the quality and reliability of the bus network. Over 26 kilometers (16 miles) of bus priority lanes were installed by reallocating roadspace on major arterial roads leading to central London, and throughout the central business district.* In 1997, 337 million bus kilometers of service were operated in London. By 2003, there were 437 million bus kilometers of service (34\% increase), and in 2009, 483 million (Transport for London, 20010; 2013). Some of these expanded service kilometers were new bus routes, but mainly they were increased frequencies and longer service hours on existing routes. By 2009, nearly 100 of London's 700 bus routes were running 24 hours per day.*

Transit ridership grew as capacity expanded, increasing the reach of rail and bus networks and therefore the catchment area for new passengers. But quality upgrades to vehicles, stations and bus stops also attracted new riders out of choice. Over 200 stations were refurbished to relieve overcrowding and improve disabled access and bicycle parking, and over 7,000 bus stops were upgraded with lighting (Transport for London, 2005). A major communications campaign called Legible London installed new wayfinding signage at all rail stations, bus stops, and major intersections. The signs all follow the same design and give information about the route and frequency of service, as well as maps of the local area. In 2003, a smartcard ticketing system was launched, the Oyster card. Smartcard readers were installed in all Underground stations and buses, significantly reducing boarding times and easing transfers.

\footnotetext{
1 Personal Communication. John Barry, Head of Bus Network Development. London, 2014.
}

From 2005 to 2010 , over $£ 200$ million was invested in walking and cycling improvements throughout London (Transport for London, 2005). In central London, traffic signals were retimed to favor pedestrian crossings over traffic throughput. In 2008, a bicycle share system was launched, boosting the trend of commuting by bike. High volume tourist areas such as Trafalgar Square and Exhibition Road were redesigned to enhance pedestrian comfort and safety. In contrast to the systemic overhaul and consistent design which characterized transit system improvements, many bicycle and pedestrian infrastructure enhancements were experimental in nature.

A visitor biking around London will find a variety of designs for bike lanes, signalized crossings, and parking in use. Transport planners monitor use patterns and user feedback. For instance, in the early 2000s, a network of blue bicycle lanes were painted on high-volume arterial roads. Called 'Cycle Superhighways', the idea was to give cyclists capacity on high speed routes, allowing them to cut through London's Victorian tangle of side streets. However, the blue paint was not well respected by drivers and cyclists using the lanes complained about contending with parked cars, leapfrogging buses, and sudden turns by cars. Therefore in 2014, a new generation of cycle superhighways was unveiled (Figure 3).

\section{Lessons learned from the London experience}

An important caveat to keep in mind, when thinking about whether these sort of effects could be achieved by similar policy interventions in other cities, is that London is an ancient city with good bones to build on. Its core, inside the charged area, still has pedestrian-scale streets laid out by the Romans 2,000 years ago and during medieval times. During the Victorian era, a dense railway network was developed, including fifteen rail stations and the first ten lines of the Underground system. These stations and right of ways have been in near-constant use, or redeveloped to meet changing needs, over the past 150 years. London's highly transit accessible center helped it develop into a monocentric city where employment is concentrated in the central business district. So we are at a disadvantage in a lot

Figure 3: Near Stratford, the newest generation of bicycle superhighways segregate bicycle and bus traffic.

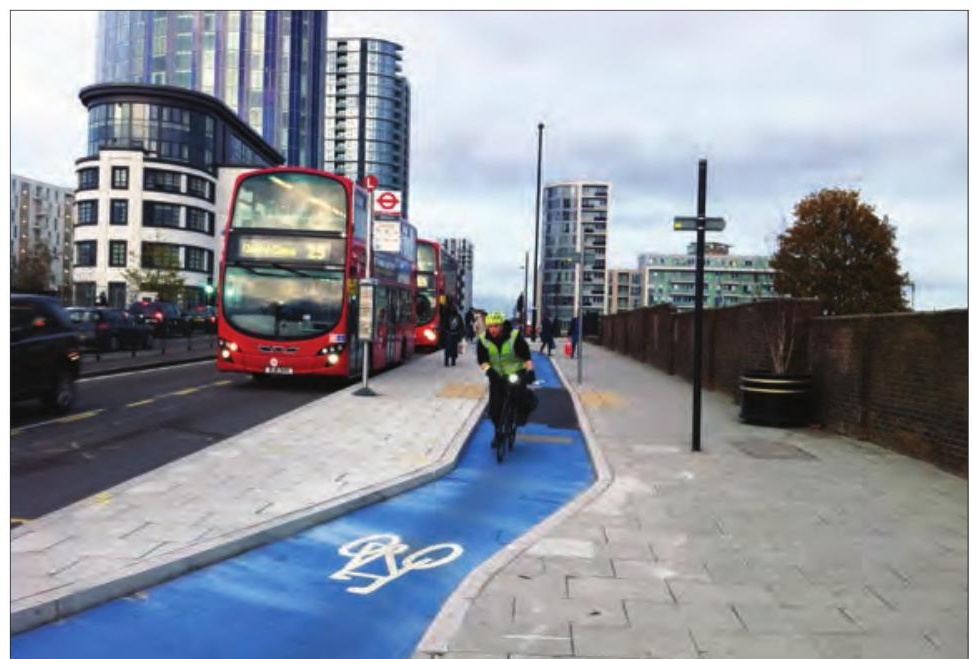


of the American cities that we work in, where high capacity public transportation infrastructure is lacking.

Another important caveat is London's regional approach to transportation. Since 2000, London has had a regional agency, Transport for London (TfL), which is responsible the entire public transportation system and a strategic regional network of arterial roadways. It is an integrated, powerful agency that owns and manages all rail, Underground, bus and taxi services in the 600 square mile London region. This change in governance structure made transit system integration, repair and modernization possible. It enabled a systemic approach, meaning transit network capacity could be improved quickly and at scale. TfL is headed by a directly elected Mayor who has executive authority over the agency. This means an elected official who is directly accountable to the public for transportation outcomes. Maintaining high levels of customer satisfaction with public transportation is a key part of retaining the office. Therefore the Mayor's office engages in frequent public outreach and polling. This combination of centralized authority and visible accountability helps ensure that service levels are equitable throughout the region, rather than varying based upon the economic status and political will of each locality.

I think there are a few lessons from the London experience that are relevant for American transportation planners. First, setting mode shift as an explicit policy goal and using paired carrot and stick measures to achieve it. In the US we are often reluctant to say that getting people out of cars is a policy goal, and we use measures that reduce capacity for private autos, like reallocation of roadspace or pricing, very sparingly. When used, they are deployed on a small scale for discrete projects. London's example shows the value of engaging in public debate about priorities. It shows that utilizing a combination of measures, especially linking them together, can be effective in winning public support and legitimize more controversial measures.

Another lesson learned is about the power of quality improvements to attract new transit riders. Measures like increased frequencies and service hours, refurbished stations and stops, and new vehicles were powerful attractors of choice riders in London. Communication strategies like Legible London and smartphone-friendly route planners made the transition easier for people. Clearly, this was only achievable in London after a pro-transit government came to power at the national level. However, in the United States we have more locally-controlled sources of funding that could be used to upgrade transit to be more reliable, comfortable, and smartphone-compatible. One step that TfL took to improve communications was free: data feeds are published online for developers to use and develop apps like route planners (also known as Application Programming Interface specifications, APIs). Some Uinted States transit operators have begun to do this, and I think we should see more.

Finally, London's willingness to experiment has helped it remain nimble and responsive to rapidly changing conditions as volumes of bicyclists and pedestrians increase. Installing

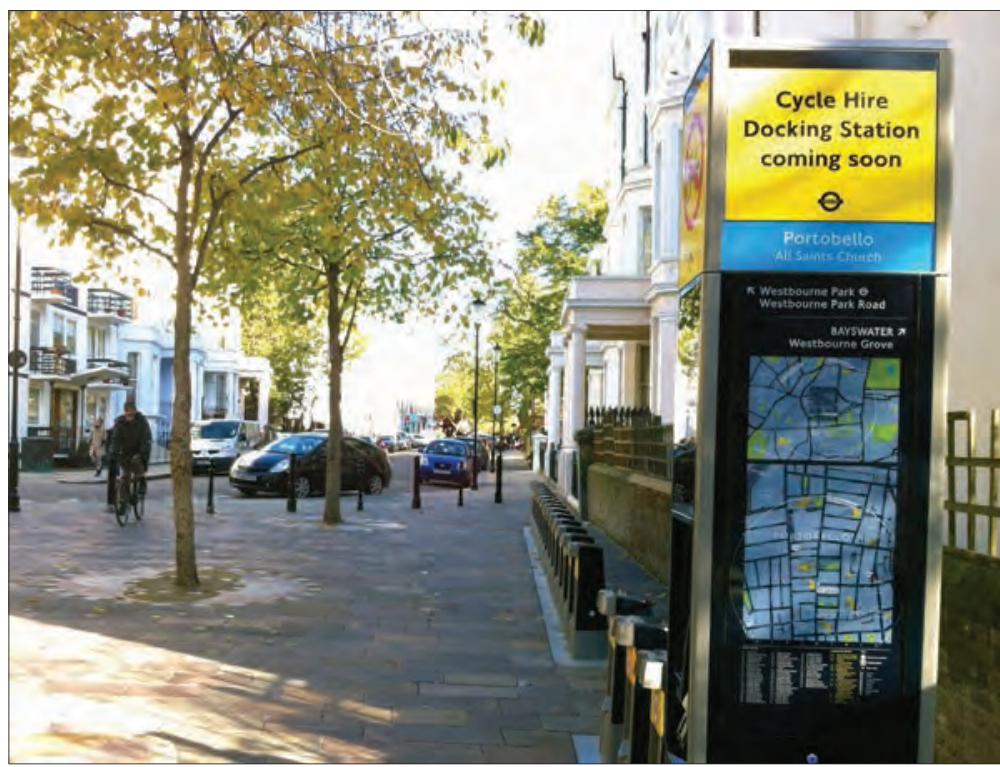

Figure 4: In Notting Hill, a street was closed to divert traffic and create a pedestrian plaza with a bikeshare station. The sign is an example of the Legible London wayfinding system.

a variety of designs and monitoring use patterns and user feedback has allowed transport planners to rip out the facilities that do not work and scale up the ones that do. Planning for bicycles in urban areas is a young field, and I think we need some way to learn what works. Experimentation can be problematic in the United States, where traffic engineers are held liable for their designs. Some cities where bicycling is growing rapidly, like San Francisco and New York, have managed to experiment with new bicycle and pedestrian designs as pilot projects. I hope we will see that kind of experimentation spread to more cities.

\section{Conclusion}

The aim of my talk here at San Luis Obispo today was to tell you a little bit about what's going on over in London, and to inspire you. Mode shift on a large scale is possible. Urban areas are growing, demographics are changing, and people are less interested in being stuck in cars. The future looks bright for planners interested in sustainable transportation.

\section{References}

Transport for London. (2003). Congestion Charge Impacts Monitoring First Annual Report. London.

(2005). Five-year Business Plan. London.

(2008). Congestion Charge Impacts Monitoring - Sixth Annual Report. London, 2008.

(2010). Travel in London - Report 3. London.

(2013). Travel in London - Report 6. London. 